\title{
IZOBRAŽEVANJE V MUZEJU: ANIMIRANJE ZA KULTURNE SPREMEMBE Pogovarjali smo se s Sonjo Kogej Rus
}

Muzeje razumemo kot ustanove, ki poleg svoje osnovne dejavnosti tudi izobražujejo. Nekateri avtorji ${ }^{1}$ pa menijo, da je izobraževanje in učenje celo ena od osrednjih nalog muzejev. Z izobraževanjem nagovarjajo različne ciljne skupine, saj so programi zelo različni. Gibljejo se od radikalne muzeologije in muzejskega aktivizma s subverzivnim izobraževanjem do participativnega učenja in razmišljanja o individualnih spominih, doživetjih, čustvih. ${ }^{2}$

Veliko izkušenj z izobraževanjem imajo v Slovenskem etnografskem muzeju, ${ }^{3}$ kjer je Sonja Kogej Rus, po izobrazbi etnologinja in zgodovinarka, kustosinja pedagoginja (od 1993) in muzejska svetovalka (od 2006) ter vodja Oddelka za muzejsko pedagogiko in andragogiko. V tem muzeju že 25 let opravlja pedagoško in andragoško delo, snuje izobraževalne programe in projekte, razstave ter predvsem odkriva zmeraj nove poti.

\section{Kustosinja pedagoginja, to se zdi star naziv. Še ustreza temu, kar v resnici delate?}

Izraz smo "podedovali« iz prejšnjih časov in verjetno bi bilo treba razmisliti o novem poimenovanju moje in vloge mojih kolegov. Danes gre za veliko vrst učenja, povezanega z muzejskimi zbirkami, manj pa za tradicionalno vodenje po razstavah kot nekoč. Spodbujamo učenje, zaradi katerega mislimo, čutimo, ravnamo drugače, postavljamo drugačna vprašanja, odkrijemo drugačne odgovore, se spremenimo. Spodbujamo učenje za spremembe.

Danes si v našem muzeju prizadevamo za tako učenje, ki spodbuja doživljanje lepote in umetnosti, družbeno vključenost, skupnostno izobraževanje v lokalnem okolju ali v posameznih mestnih četrtih in tudi lokalni razvoj. Pri tem imamo v vseh muzejih v Sloveniji podobne težave: premalo nas je, ki delamo le na področju učenja in izobraževanja.

1 Anderson, D., Cosson, A. in McIntosh, L. (ur.) (2015). Research Informing the Practice of Museum Educators. Boston: Sense Publ.

2 Clover, D. E., Sanford, K., Bell, L. in Johnson, K. (ur.) (2016). Adult Education, Museums and Art Galleries. Boston: Sense Publ.

3 http://www.etno-muzej.si/ 
Številni delajo hkrati še na drugih področjih. Jaz sem zadovoljna, da imam okrog sebe skupino mladih in zavzetih študentk, ki mi pomagajo.

\section{Komu je namenjeno vaše delo? Kaj obsega?}

Pedagoške službe snujejo programe za tiste, ki prihajajo v muzej organizirano (vrtci, šole, odrasli, turisti), kot tudi programe za posameznike, otroke in družine. Znotraj tega so tudi tako imenovani popularizacijski programi, kot so sobotni programi ali pa programi ob dnevih odprtih vrat. Zdajšnji andragoški program pa obsega delo s kulturnimi mediatorji, osebne razstave - bom razložila, kaj to je - in druge programe za odrasle. Tu sodelujem z našimi kustosi. Pedagoško-andragoško delo ni več le tradicionalno vodenje obiskovalcev po razstavah, marveč so to programi, ki smo jih zasnovali in so v povezavi z raznolikim muzejskim občinstvom, ciljnimi skupinami in temami. Tudi če je le vodenje po razstavi, se to pogosto nanaša na določeno temo, kot so spomin, nostalgija, prijateljstvo ... To obiskovalcu zagotavlja, da ne bo le gledal in poslušal, marveč bo dogajanje celovito doživel, v dogajanje bo vložil sebe.

\section{Kako nekdo postane muzejski pedagog ali muzejska pedagoginja?}

Muzejske pedagogike ali kulturne mediacije v Sloveniji za zdaj ni mogoče redno študirati ${ }^{4}{ }^{4}$ zato so zaposleni na teh področjih izobraženi v svojih strokah, imajo disciplinarno znanje, ki ga dopolnijo s pedagoško-andragoškim znanjem. Mogoče so različne kombinacije, a nenehno izobraževanje in samostojen študij sta nujni del našega profesionalnega dela.

\section{Dejali ste, da v tem muzeju rastete tako dolgo, kot raste naša država. Petindvaj- set let?}

Pred 25 leti smo gradili ne le državo, marveč tudi to našo lepo stavbo in to našo muzejsko četrt. In takrat sta se rodila tudi moja otroka. Spremljala sem njun razvoj in znanje prenašala na muzejska tla $v$ otroške programe. Med življenjem in delom je le tanka močno prepustna meja. Moje muzejsko občinstvo so bili takrat otroci in mladi. Zdaj pa, se mi zdi, raje delam s starejšimi. Včasih se mi je sicer zdelo, da sem premlada, da bi starejše dobro razumela, pa sem vseeno 17 let delala s starejšimi študenti Slovenske univerze za tretje življenjsko obdobje. Tudi kulturni mediatorji so izšli iz skupnega projekta muzeja in univerze. V muzeju smo zanje skupaj našli vloge, ki jih sprva nismo predvideli. Taka nova vloga je vodenje Galerije pripovedovalcev, ko kulturna mediatorja spodbujata obiskovalce k sodelovanju, da potem posnameta njihove pripovedi na film. Galerija pripovedovalcev je rastoča zbirka osebnih pripovedi, ki obiskovalcem razstave in naše spletne strani omogoča vpogled v razmišljanje drugih ljudi o sebi, svojem okolju in bližnjih, o

4 Program muzejska pedagogika ponujajo kot drugostopenjski magistrski študijski program (izredni študij) na Pedagoški fakulteti Univerze v Ljubljani (https://www.pef.uni-lj.si/801.html). 
narodu, državi, veri in jeziku, o svoji in naši dediščini, o svoji ali tuji drugačnosti, o vrednotah, pogledih na življenje in smrt, torej o temeljnih identitetnih vprašanjih. Kulturne mediatorke delujejo tudi še na drugih področjih: v restavratorskih delavnicah, vodijo po razstavah, kjer se izkazujejo za imenitne sogovornice prav skupinam starejših. Pri nas so bili starejši kulturni mediatorji preboj tudi zato, ker prej nismo imeli prostovoljcev in smo lahko tako začeli odkrivati prostovoljstvo. Zdaj bi radi dejavnost razširili. Želimo si še prostovoljnih ambasadorjev muzeja, ki bi še več delali med ljudmi, ki bi lahko šli do različnih študijskih krožkov in bi starejšim prinašali muzej v njihovo okolje ali pa jih navdušili za obisk muzeja.

Eden izmed rastočih obrazstavnih programov našega muzeja so osebne razstave obiskovalcev. Ko smo pred desetimi leti postavili razstavo Med naravo in kulturo, smo v ospredje dali predmet. Skozi zgodbo o preživetju, potrebnem in nepotrebnem, duhovni in socialni kulturi smo pokazali, kaj naš muzej zbira. Potem je projekt rasel in dopolnili smo ga z razstavo Jaz, mi in drugi, podobe mojega sveta. Vsakdo je lahko del te razstave, se najde v njej, se sprašuje o sebi. Z Janjo Žagar, avtorico razstave, sva se odločili, da bodo naši obiskovalci prispevali pripovedi o sebi. In nastalo je že več kot 30 takšnih razstav!

\section{Kako to gre?}

To so razstave, ki temeljijo na zasebnih predmetih, fotografijah iz osebnih ali družinskih albumov, shranjenih dokumentih in podobno. Avtorji razstav so obiskovalci sami, v pomoč pri tej posebni muzejski izkušnji pa imajo na voljo muzejskega mentorja - za spodbudo, tehnično usmerjanje. Avtorji po svoji presoji in s svojimi besedami predstavijo in poudarijo vsebine, ki najbolj nazorno kažejo njihovo življenjsko pot, in jih delijo z njim pomembnimi posamezniki in drugimi obiskovalci muzeja. Izbrani poudarki in načini interpretacije osebnih vsebin zato niso stvar strokovnih muzejskih presoj, ampak oblika avtorjeve samorefleksije. Osebne razstave so muzejska oblika avtoportretnih zgodb, ki v naracijo o sebi hote ali nehote vključujejo tudi druge ljudi in splošne družbene razmere. Skozi zgodbe zbranih spominov, izkušenj in spoznanj avtorji razkrivajo svoje pripadnosti različnim vlogam, ljudem, institucijam, krajem, zanimanjem ... Ker tudi najbolj osebne zgodbe, predmeti in pomeni vsebujejo elemente skupnega, se med pripravo razstave okrepi zavest avtorjev o povezanosti lastne zgodbe s skupno preteklostjo, osebne dediščine s skupno in tudi muzejsko dediščino.

Vsak snovalec osebne razstave je posebna zgodba. Snovalci osebnih razstav so starejši posamezniki, skupine, posamezniki iz ranljivih skupin, kot so brezdomci in invalidi, umetniki, zbiralci, pa tudi študentje. Študentje Oddelka za etnologijo in kulturno antropologijo so denimo pripravili osebno razstavo na temo prehodov \#vstopil SEM, študentka biologije pa razstavo Majica, pripadnost in spomin. Predstavila se je kot tabornica, gimnazijka, plesalka in študentka biologije, in to z majicami, fotografijami, predmeti. 


\section{Nastajanje takšne razstave gotovo okrepi medsebojne vezi.}

Če osebno razstavo pripravlja skupina, to zelo okrepi medsebojne vezi, saj potem razmišljajo tudi drug o drugem. Naj kot primer navedem skupino Podobe mojega sveta. To je študijski krožek in starejše članice študijskega krožka so se predstavile »skozi« svoje čevlje, poročne, moževe gojzarje ... Predmeti so svojevrstna reprezentacija življenja lastnice, lastnika in dogodkov, povezanih s čevlji. Predmeti sprožijo razmišljanje o sebi in pojavi se želja, da bi razmišljanje delil z drugimi. Za naš muzej je sodelovanje obiskovalcev, kulturnih mediatorjev in drugih pomembno.

\section{Projekt kulturnih mediatorjev, ob katerem se povezujeta muzej in univerza za tre- tje življenjsko obdobje, se zdi zanimiv, ploden za vas in univerzo, predvsem pa za starejše.}

Radi bi razvili kulturo obiskovanja muzeja, za obiskovalce se moramo »bojevati«, zato pripravljamo dneve odprtih vrat, povezujemo se z različnimi skupinami: starejšimi, mladimi, azilanti, brezdomci, družinami. Ljudi je treba navduševati, povezovati; ustvariti želimo oseben, personaliziran stik s predstavniki različnih skupin občinstva, kar dosežemo skozi razstave, razprave, delavnice, skupnostne stvaritve in podobno. Upoštevati moramo različne značilnosti in različne zmožnosti obiskovalcev, denimo starost, družbeni status, način življenja, vrednostni sistem, tradicije, hendikepe. Uvajamo inovativne oblike participacije v kulturi, pa tudi nove oblike posredovanja znanja ter menjave kulture med posameznimi kulturnimi okolji.

\section{Dejali ste, da imajo muzejski predmeti tudi svojo simbolno raven.}

Seveda, lahko simbolizirajo prijateljstvo, lahko budijo nostalgične občutke, simbolizirajo ljubezen. Brusni kamen, denimo, na simbolni ravni izraža ljubezen. Ljubezenska darila so si dajali tudi nekoč. Pa ne le robčke! Trnič, denimo, je mladi sir, ki ga delajo na Veliki planini. Pastirji so ga oblikovali v čebulice in okrasili z lesenimi pisavami. Okrašeni sir so stisnili v obliko dojke. Takšne sirčke so pastirji dekletom podeljevali v paru, dva sirčka za eno dekle. Simbolno, vsekakor. Včasih so fantje dekletom podarjali tudi rezljane preslice. Na takšni se je zbodla Trnuljčica. Simbolna raven predmetov nam odkrije marsikaj. Prijateljstvo, na primer, se je izražalo v fantovskih združbah ob praznikih. Pustovali so, šemili so se.

Pri nostalgiji gre spet za nekaj drugega. Zanima nas, kateri razstavljeni predmet v posamezniku zbudi občutke iz mladosti. V muzeju smo zbirali predmete - in to še danes počnemo - vendar jih ne zbiramo le zato, ker so lepi, temveč tudi zato, ker so nosilci spomina. Zanima nas človek, ki takšen predmet uporablja, in raba predmeta. 


\section{Razvijate tudi projekte, ki se nanašajo na življenjske prehode, tranzicije.}

Največ življenjskih tranzicij nastane $\mathrm{v}$ poklicnem delovnem obdobju, malo v prostem času, malo v povezavi z dejavnim državljanstvom. Po upokojitvi je manj prehodov. Tranzicije so v sodobnosti zelo osebne, pri vsakomur so drugačne. Hočem reči, da se ljudem dogodijo različni prehodi, ki so individualizirani. Javne pa tranzicije postajajo s pomočjo tehnologije, socialnih omrežij. Prav projekt študentov etnologije in kulturne antropologije je obravnaval teme, kot so moje prvo potovanje kot prehod, prvi seks, prva menstruacija. Pripovedovalci so se povezali med seboj. Koordinirali so se, da je vsak povedal svojo zgodbo, in jo povezali s celoto. $\mathrm{V}$ tem letu bomo v Slovenskem etnografskem muzeju obravnavali družinske zgodbe. Kolegica Polona Sketelj se pogovarja z izbrano zamejsko družino. Izpraznili bomo njihovo podstrešje in ga preselili v Ljubljano. S predmeti bo prišlo k nam morje, ribištvo, vonj po soli ...

Pogovor s Sonjo Kogej Rus je tekel, kot teče novi roman, tiste vrste roman, ki se začenja nekje na sredi in se ne konča. Človeka, predmete, čustva, razum, podobe življenja in še marsikaj smo našli v tem pogovoru, izseku iz njenega dela in življenja. Sonja Kogej Rus prejema od obiskovalcev, študentov, sodelavcev veliko. Zakaj? Formula je preprosta: veliko daje. Ve, da je v muzeju vse prepleteno, da človek, strokovnjak postane to, kar je, zaradi medsebojnih povezav in skupnih naporov. Ko pripoveduje o svojem delu, pravi »mi«.

Pogovarjala se je Dušana Findeisen. 